\title{
Research of Modern Enterprise Performance Management
}

\author{
Nan $\mathrm{Zhou}^{1}$, Haohao $\mathrm{Li}^{2}$ \\ ${ }^{1}$ Jiangxi Institute of Economic Administrators, Nanchang, Jiangxi, 330038 \\ 54892713@163.com
}

Keywords: Enterprise Performance; Enterprise Management; Improvement and Development of Financial Status

\begin{abstract}
With the advent of economic globalization, Chinese enterprises, especially small enterprises are facing increasingly fierce competition, to their own enterprises in the competition more than any other business advantage, we must pay attention to the talent competition, talent management, attention to corporate performance management, but more importantly, to find a suitable and enterprise performance management theory phase, find the best combination of practical and theoretical way enterprises, is the most important task.
\end{abstract}

\section{Introduction}

In 1984, HJ. Bernardin proposed "to within a certain period of time, by a particular job functions or activities create outputs and recording." That performance is a result of the performance, which is considered the most popular scholars view the performance point of view. There is another point of view is considered to be acts of. Brumbrach in 1988, made a "behavior and results." Murphy asked, "Performance is a set of behaviors associated with a work-related organization or organizational goals" in 1990. Campbell in the same year that "Performance is synonymous with behavior, it is the actual action of people, and can be observed. By definition, performance is not the result of behavior, but the act itself ..."

In recent years, because scholars have in-depth study, performance concept has been further sublimation. At this stage, that the performance is a combination of behavior and output is the most common point of view. In 2010, Chinese scholars Lin Xinqi then "Performance" explanation is a combination of output and behavior, it refers to the collective or individual control, and established a series of behavioral objectives and results.

\section{Employee Performance Management Situation}

Performance management is Western scholars first proposed, the current knowledge-based performance management status of domestic enterprises in the exploration stage, through comparative analysis and empirical method, the specific conditions of the knowledge-based performance management employees are summarized as follows: the ability to manage staff performance management is weak, cause performance system can not play an effective implementation of the results, performance management for administrator communication, coordination and decision-making management capabilities make high demands. Oral corporate managers pay attention to performance, but in the course of the performance, there is no a relaxed working environment, lack of communication both horizontal and vertical, the higher the staff indifferent, various departments within the organization carry out their duties, will not employees work to give support and cooperation, leading to the company's performance management enforced.

Business management foundation is weak, some companies invited foreign monks, first to sort out the strategy, process reengineering, organizational redesign, then do performance management, the whole process is full of hardships, because it ignores the difficulty of change, such as ignoring corporate performance atmosphere The build and psychological guidance of employees, causing strong resentment of employees. In addition, the company introduced some "ism", not from the actual situation of the company itself, and direct use of other company's performance management system, this will cause the one hand, companies can not properly understand the performance 
management, on the other hand, companies can not a correct understanding of the performance of employees and their influence factors of knowledge, and thus can not establish a scientific performance management system.

Company performance appraisal results either quantitative or qualitative assessment evaluation. Most Chinese companies based on qualitative assessment, although some companies are borrowing a lot of assessment tools to develop the relevant indicators for quantitative assessment criteria evaluation, but the results are poor, and more importantly, the performance appraisal process into a walking, ignoring the collection of data, assessment lack of objectivity and fairness; some companies excessively pursue the quantitative evaluation index, a considerable part of the work of knowledge workers is difficult to quantify, if difficult to quantify the results are barely quantified, or select quantitative indicators but does not reflect the employees actual performance show, will result in performance management lack of objectivity and fairness; hastily performance evaluation, assessment results subjectivity, the assessment results can not get good use, there is no suitable match incentives.

\section{Employee Performance Factors}

Draw on a variety of domestic and international factors affecting performance, such as Vroom (1964) that the employee performance is the ability and incentives of these two factors. When these factors get variables mainly covers the work necessary knowledge and information resources, then working environment and conditions, work practices or work process guidance, counseling and support leadership. Einhorn and Hogarth (1983) that "the performance formula P = f (s, m, o, e) performance- performance, skill- skills, motivation- incentives, occasion- opportunity, environment- environment, f-- the factors mentioned above inspection The functional relationship) "; Campbell (1993) that" the employee's performance has three main determinants: declarative knowledge, procedural knowledge or skills, motivation, they are considered work directly related determinants, he also believes environmental factors on performance also has a great influence, such as the characteristics of the different quality of equipment, tasks, features work duties, the level of support staff working conditions nature can also lead to differences on employee performance. " Domestic scholar Zhang Jixun argues that knowledge workers and the working environment is a system. Therefore, I believe the performance of knowledge workers produce not only subject to the employees themselves, but also subject to the organizational climate, performance they produced is the result of its own staff and the working environment interaction. On the one hand the use of high performance atmosphere characteristic of knowledge workers to meet their desire to learn, to improve the capacity of staff; on the other hand, internal full share knowledge, enhance core competitiveness overall organizational performance and organization. Based on performance factors, presented a performance evaluation indicators are indicators of competency.

\section{Employee Performance Management Difficulties}

Important and difficult employee performance management in employee performance appraisal results when and how to equitably assess the results of complex labor work, how to design a reasonable performance evaluation indicators, to objectively evaluate the results of their work. Knowledge of the employee's performance can not be measured only in the results and the number of, mainly in the following reasons: In the first, in most cases, knowledge workers complete a task, in addition to working alone, and in collaboration with other team members, employees operating results are not necessarily produced by the employee's behavior; second, the workflow can not be unified standards, manage knowledge workers not as a general laborer management or operational staff to manage, but can not use certain standardized process requirements knowledge worker has reached the control and management; and third, the result is difficult as a measure of performance standards, on the one hand, the results are often unpredictable, difficult to achieve clear objectives set, on the other hand, it is difficult to make a comprehensive work results reasonable measure. 
After the end of the project can not be recovered due to the external environment as reasons for the corresponding payments, resulting in bad debts, we can not blame the staff for design and construction. Some employees usually very hard work, but the result was unsatisfactory, it can not therefore ignore the contribution made by employees who organized; fourth, knowledge employee performance is difficult to quantify, because their work is primarily thinking of, labor process often intangible. Therefore, knowledge workers in the performance appraisal time, not only to score, but to them implement effective performance management, performance management through a systematic process to enhance the knowledge of the employee's performance and enhance their value.

Therefore, according to this stage knowledge-based enterprise performance management status and performance management difficulties, the design performance management system must also establish the appropriate management system to ensure effective implementation of the performance management system. Secondary indicators for performance assessment task design, and according to the task and set the standard, not for assessment and evaluation, the results of the project management tasks in the form of knowledge-based enterprises are to measure all the results of the task was complete and the project completion schedule for the assessment criteria.

\section{The Establishment of Performance Management Systems}

Because the knowledge-based employees have independence, they exist thinking alienation, coupled with the company's previous PACT no formal performance management system, in order to allow employees to accept the company at all levels need to establish the values we all agree, can not let the performance decline of the land was rejected; the company implemented by passing the purpose and significance of performance management at all levels, and to inform the implementation of the benefits of employees, triggering enthusiastic staff performance management system implementation; performance management is not the ability of the minority, but should become the common ability of managers, continued in-depth learning and practice. Therefore, before the formal implementation of performance management is not a mere formality, we must start from the basic work. Two major infrastructure work: job analysis, performance management training to establish performance management awareness; knowledge management culture, organizational learning, the formation of a high-performance environment. Therefore, PACT companies should do the following basic tasks: establish performance management awareness and the formation of a high-performance environment.

Design goals and principles of objective performance appraisal and performance management systems is consistent. PACT company is project-oriented team organization, each employee is the company's resources, the structure of each employee's knowledge, ability and character are different, management attention to humanity, cooperation and flexibility, in order to better reflect the company's "people-oriented "management philosophy to, because of job performance evaluation index design varies from person to person, vary over time, through good organizational climate and internal communication channels, superior performance management initiative to inspire employees, improve employee performance, improve the capacity of staff so that employees really get growth and recognition.

Knowledge is knowledge-based production resources and tools employees use at work, knowledge-based enterprise tasks only with appropriate knowledge of knowledge workers to be competent, therefore, the task objective requirements of its people capable to do it. Knowledge-based enterprises task uncertainty, no longer a long-term stable and unchanging elements, PACT's project is unique and special, employees undertake common work tasks dwindling, the task will continue to change, thus the knowledge and skills needed to complete tasks than also complicated on a particular task, the one employee but on their own understanding of the professional, can only make a partial contribution to solve the problem, which requires employees around a specific task to work together, to work together on a variety of knowledge workers are becoming increasingly relevant requirements increases. Meanwhile, in view of the characteristics of the project company's business, the company developed the product and its implementation by the 
degree of restriction. So far, though PACT company has its own mission and vision, but company executives in the company's development strategy and tactics not fully rolled out quickly, but uphold their own values, steady win. Therefore, in order to ensure the company's current development and future business development, in order to achieve the company's development goals, critical success factors and further analyze the company's key success factor is to ensure the company's continued development, and has been in the field of management of the company concerned, but also enterprises to maintain Key competitive market, and the key personnel possess the ability to ensure the development of the company. After leaving PACT human resources, the company would have nothing, so from people starting to define performance indicators to assess levels of PACT staff competence index. It is precisely because the company has been owned PACT talent, today to get sustainable development. That in the end is what prompted the company key competency today's development? In the study on the basis of competency theory, the first of knowledge and skills to complete the task in the history projects needed for analysis, and to analyze the tasks of knowledge workers collaborate personality traits, and finally through the upper, middle managers and specialists brainstorming, the following key success competencies: strategic thinking, analysis and judgment, ability to execute, customer-oriented, professional ability, negotiation skills, communication and influence, the spirit of cooperation, trustworthiness and reliability, responsibility, learning and innovation, time management, team management. Followed by the above competency classification again, they can be divided into core competencies, professional ability, general ability. In order to allow management and employees understand competency requires detailed definition and with the corresponding behavior and inefficiencies efficient capacity are described. This paper selects representative of PACT business execution culture competency - inefficient behavior demonstrated by the execution and efficient conduct described.

\section{Conclusion}

Broadly speaking, any management activities is to improve the practice of organizational performance, such as operations management, supply chain management, human resource management, and even corporate culture and management, and profit is no longer the ultimate goal of enterprise performance management. As the owner of the enterprise as a whole from the perspective of the external evaluation and control overall performance is undoubtedly necessary. As a social activity unit, companies must have a clear development goal, through the consumption of social resources and social value of the corresponding output, assume the corresponding social responsibilities. Performance Evaluation business owner perspective is to be seen as a black box (or gray box), and analyzed by its inputs and outputs, the effect of corporate management, social contribution and development potential evaluation and intervention, and as the basis for enterprise diagnosis, investment decisions, as well as the allocation of social resources and other strategic activities. This external evaluation often do not focus on business process-related input, to achieve predetermined output of specific mechanisms, but stressed that by controlling the input and output on a macro level, to induce in a predetermined direction and track the development of enterprises operating results, the input and output of the switching mechanism is seen as is an internal process, by the operator's initiative to achieve, just by the operators of the evaluation and incentives to ensure the effectiveness of the process. Obviously, this external evaluation of the practical effects to enhance the overall performance is indirect and it can direct corporate strategy at the macro direction, but the company's internal specific business activities and can not play much of a role in guiding.

\section{References}

[1] Brockne, Wiesenfeld, B. An Intergrative Framework Explaining Reaction to Decision Interactive Effects of Outcomes and Procedures. Psychological Bulletin,1996,189-208

[2] Grover Starling-Public Sector Management.2003. 
[3] J.D. Jian\& S.L. Rynesf Making Total Quality Work-Aligning Organizational Processes Performance Measures, and Stakeholders, Human Resource Management. 1991 (30): 303-330.

[4] Khim Ling Sim, Hian Chye Koh. Balanced Scorecard: A Rising Trend in Strategic Performance Measurement. Measuring Business Excellence. 2001. 